\title{
Klasifikasi Gerakan Tangan Menjadi Suara Menggunakan Neural Network
}

\author{
Muhammad Arifan Lizamanihi ${ }^{1)}$, Ii Munadhif ${ }^{1 *}$, Mohammad Abu Jami'in ${ }^{1)}$ \\ ${ }^{1}$ Program Studi Teknik Otomasi Politeknik Perkapalan Negeri Surabaya \\ *iimunadhif.its@gmail.com \\ DOI: https://doi.org/10.21107/rekayasa.v13i3.6614
}

\begin{abstract}
Indonesian Sign Language (BISINDO) is a language for people with hearing impairment and speech impairment. But sign language still has disadvantages when it is used for people who have never learned sign language that is normal people. Therefore we need a tool in the form of gloves that can translate sign language with sound output. This instrument consists of ten flex sensors, two GY521 sensors, two arduino nano, one arduino mega, a computer and android devices. There is a classification method that is a neural network with data samples of ten hand movements that have meaning (saya, kamu, bapak, ibu, adik, tidur, bertemu, apa, maaf, hari ini) and each hand gesture twenty times. Classification results vary. (saya) get 100\% success, (kamu) get $80 \%$ success, (bapak) get 60\% success, (ibu) get $20 \%$ success, (adik) get 90\% success, (tidur) get 80\% success, (bertemu) get 100\% success, (apa) get 70\% success, (maaf) get $50 \%$ success, and (hari ini) get $90 \%$ success. The overall average is $74 \%$.
\end{abstract}

Keywords: BISINDO, gloves, sensors, arduino, neural network, sound

\section{PENDAHULUAN}

Secara umum komunikasi dibedakan menjadi dua yaitu komunikasi verbal dan non verbal. Komunikasi verbal merupakan proses komunikasi melalui bahasa dan kata-kata yang diucapkan. Sedangkan komunikasi nonverbal ialah penyampaian arti (pesan) tanpa kata-kata yang tercermin pada bahasa tubuh dan intonasi verbal. Contoh komunikasi nonverbal ialah menggunakan gerak isyarat, bahasa tubuh, ekspresi wajah, dan kontak mata (Hardjana, 2003).

Komunikasi yang dilakukan oleh sesama manusia normal yaitu verbal menggunakan bahasa atau kata-kata yang diucapkan melalui lisan. Sedangkan bagi penyandang tunawicara (tidak dapat berbicara) dan tunarungu (tidak dapat mendengar) menggunakan bahasa non verbal yaitu bahasa isyarat. Menurut KBBI, bahasa isyarat bahasa isyarat adalah bahasa yang menggunakan isyarat (gerakan tangan, kepala, badan dan sebagainya), khusus diciptakan untuk tunarungu, tunawicara, tunanetra, dan

\section{Article History:}

Received: Jan, 30 ${ }^{\text {th }}$ 2020; Accepted: Dec, $6^{\text {th }} 2020$

Rekayasa ISSN: $2502-5325$ has been Accredited by Ristekdikti (Arjuna) Decree: No. 23/E/KPT/2019 August 8th, 2019 effective until 2023 sebagainya. Salah satu bahasa isyarat yang digunakan di Indonesia adalah bahasa isyarat Indonesia (BISINDO) yang dikembangkan berdasarkan budaya dan karakter komunikasi tunarungu Indonesia (Nuryazid, 2016). Meskipun telah ditemukan bahasa isyarat bagi penyandang tunarungu dan tunawicara untuk saling berkomunikasi dengan satu sama lain, tetapi bahasa isyarat masih memiliki kekurangan ketika digunakan kepada orang yang belum pernah menggunakan atau belajar bahasa isyarat sebelumnya yaitu orang-orang yang dapat mendengar dan berbicara atau orang normal. Bagi orang-orang yang dapat mendengar dan berbicara, belajar bahasa isyarat bukanlah menjadi suatu keharusan, karena mereka cukup menggunakan bahasa sehari-hari untuk berkomunikasi dengan satu sama lain. Namun, lain halnya ketika orang normal harus berkomunikasi dengan tunarungu dan tunawicara, orang normal harus mengerti terlebih dahulu bahasa isyarat yang mereka gunakan agar dapat berkomunikasi dengan baik.

\section{Cite this as:}

Lizamanihi, M.A., Munadhif, I \& Jami'in, M.A. (2020) Klasifikasi Gerakan Tangan Menjadi Suara Menggunakan Neural Network. Rekayasa, 13 (3), 270-276. doi https://doi.org/10.21107/rekayasa.v13i3.6614

(C) 2020 Muhammad Arifan Lizamanihi, Ii Munadhif, Mohammad Abu Jami'in 
Hal ini tentunya menjadi penghalang bagi keduanya saat berbagi informasi dan pengalaman. Oleh karena itu diperlukan sebuah inovasi baru untuk mempermudah komunikasi antara orang normal dan tunawicara menggunakan perangkat berupa sarung tangan yang mampu mengkonversi gerakan tangan menjadi suara.

\section{METODE PENELITIAN}

\section{Perancangan Sistem}

Gambar 1 adalah diagram blok perancangan sistem. Pada diagram tersebut memiliki tiga bagian yaitu masukan berupa dua sensor flex dan dua sensor MPU6059 GY521. Proses berupa pengendali dua arduino nano dan satu arduino mega 2560 dan keluaran berupa aplikasi android. Sensor flex masing-masing untuk tangan kanan dan kiri berfungsi mendeteksi kelengkungan jari pada saat melakukan pergerakan tangan dan jari. sensor MPU6059 GY521 masing-masing untuk tangan kanan dan kiri berfungsi mendeteksi posisi dan gerakan telapak tangan saat memberikan bahasa isyarat. Arduino nano masing-masing untuk tangan kanan dan kiri berfungsi sebagai jembatan data dari sensor dan mengirimkannya menuju arduino mega 2560. Arduino mega mengolah data agar dapat mengeluarkan suara pada aplikasi android.

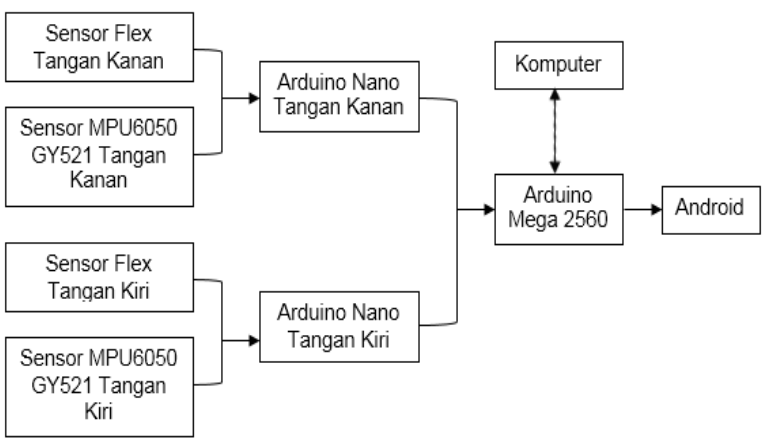

Gambar 1. Diagram Blok Perancangan Sistem

Nilai masukan sensor flex berupa resistansi. Agar dapat diterima oleh arduino maka diperlukan rangkaian pembagi tegangan. Sedangkan nilai masukan sensor GY 521 berupa sudut yaw, pitch, dan roll yang diperoleh dari konversin nilai pada sumbu $x$, sumbu $y$, dan sumbu $z$ dari gyroscope sensor. Jika nilai masukan sensor telah terbaca arduino, maka dilakukan proses klasifikasi dengan neural network sehingga perangkat android dapat mengeluarkan suara sesuai hasil klasifikasi.

\section{Perancangan Hardware}

Perancangan hardware pada Gambar 2 menjelaskan tentang beberapa komponen hardware yang digunakan. Peneliti menggunakan dua jenis sensor yang dipasang pada masingmasing tangan untuk mendeteksi perubahan posisi jari dan gerakan telapak tangan. Terdapat lima buah sensor flex dan satu buah modul sensor MPU6050 GY521. Pada Arduino Nano dan Arduino Mega 2560 juga dipasang masing-masing satu buah modul komunikasi wireless NRF24L01 agar dapat mengirim dan menerima data sensor yang telah terbaca. Selanjutnya Arduino Mega 2560 mengirim hasil klasifikasi ke perangkat Android menggunakan Modul Bluetooth HC-05.

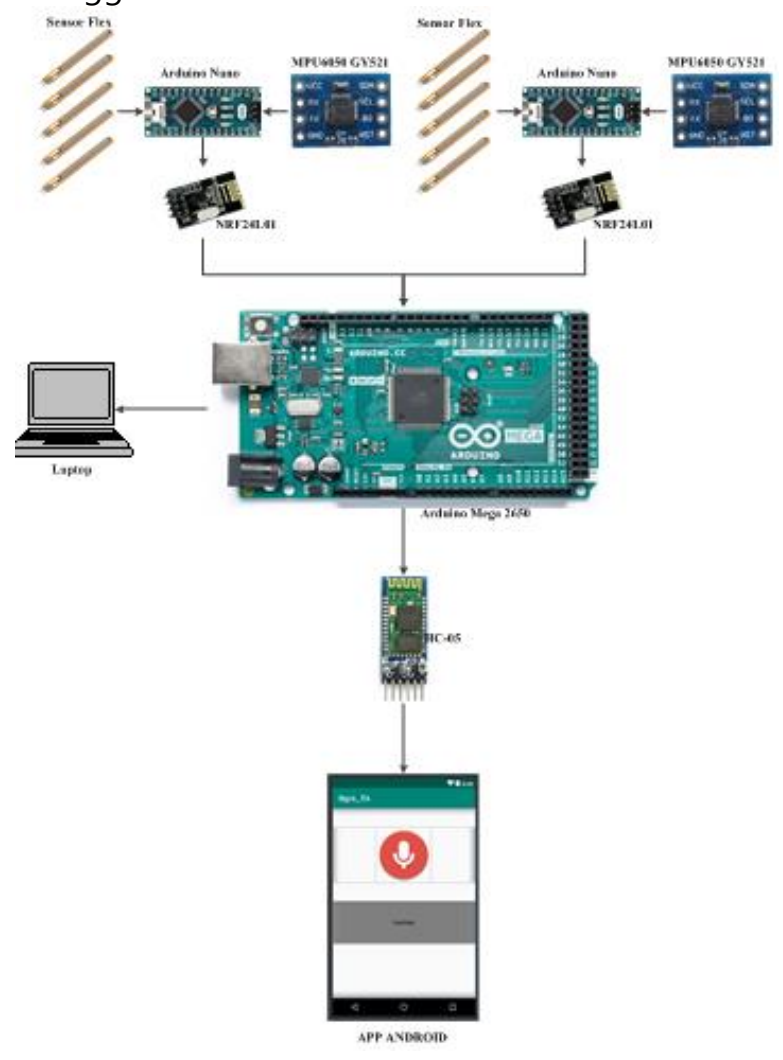

Gambar 2. Perancangan Hardware

\section{Perancangan Mekanik}

Perancangan mekanik tampak atas pada Gambar 3 menunjukkan posisi sensor flex dan MPU 5060. Sensor flex ditempatkan pada masingmasing jari dan sensor MPU5060 ditempatkan pada punggung dari telapak tangan. Terdapat kontrol box yang digunakan sebagai tempat pengendali arduino dan sumber tegangan. 


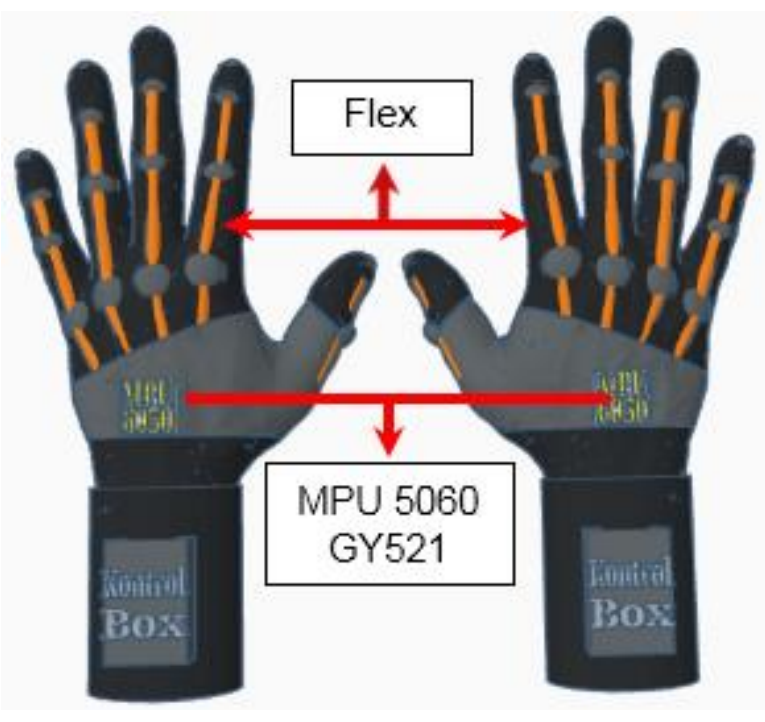

Pengambilan Data Sampel

Untuk mendapatkan data sampel dilakukan dengan cara uji coba pada sarung tangan penerjemah bahasa isyarat sekaligus merekam data sensor dan diteruskan ke arduino mega 2560. Terdapat 10 gerakan bahasa isyarat BISINDO pada saat pengambilan data dan masing-masing gerakan bahasa isyarat harus di ulangi sebanyak 20 kali, sehingga secara keseluruhan didapatkan 200 data sampel. Datadata tersebut dikelompokkan menjadi dua kelompok yaitu kelompok data gerakan satu tangan dan kelompok data gerakan dua tangan. Tabel 1 menunjukkan 10 gerakan sampel bahasa isyarat yang digunakan pada penelitian ini

Gambar 3. Perancangan Mekanik

Tabel 1. Gerakan Sampel Bahasa Isyarat

No. $\begin{gathered}\text { Expresi gerakan } \\ \text { isyarat }\end{gathered}$




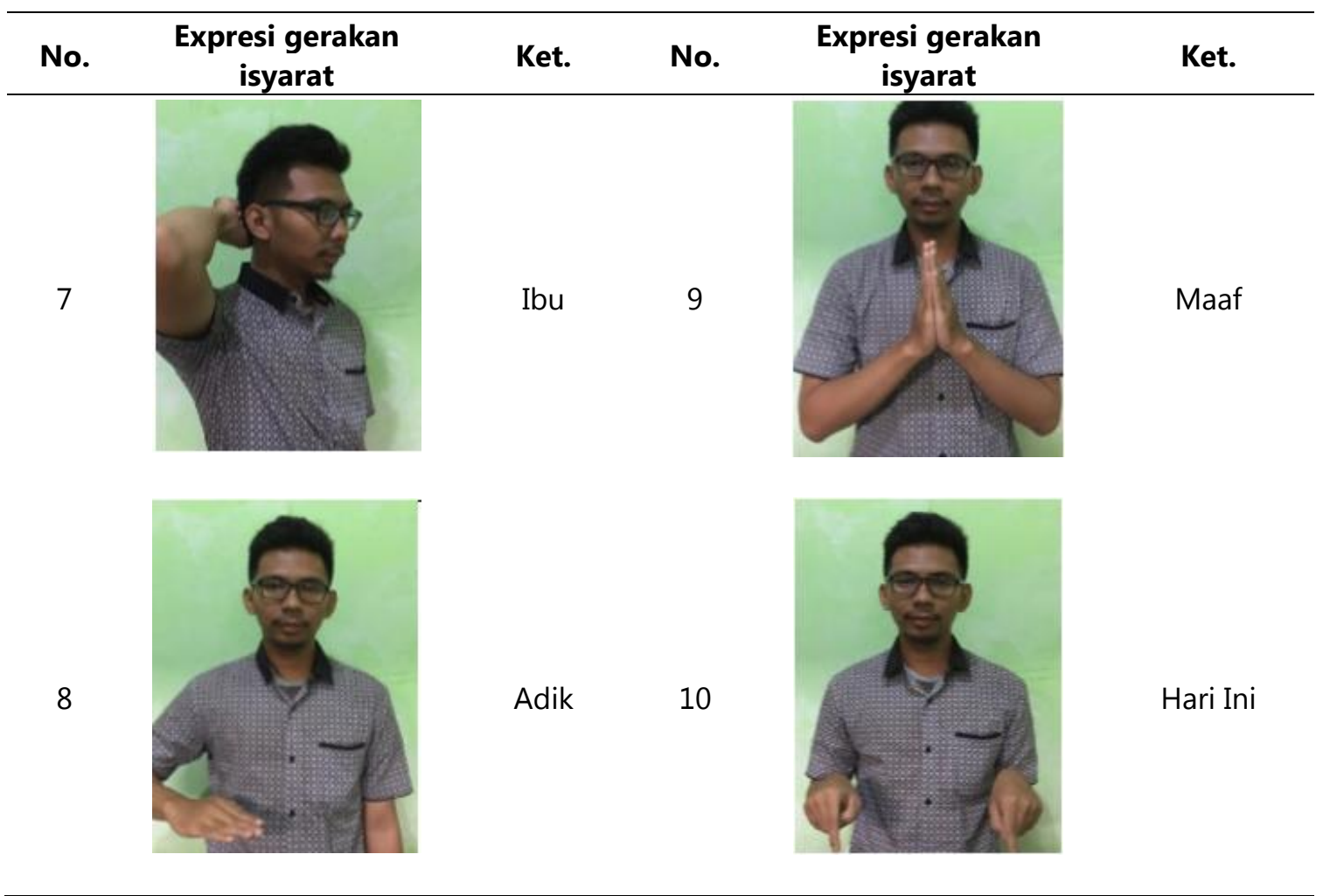

\section{Training data dengan neural network}

Pada proses training data, 200 data sampel ditulis dalam bentuk matriks. Data yang telah terkumpul dikelompokkan menjadi dua yaitu data dengan masukan 8 (satu tangan) dan masukan 16 (dua tangan). Matrik output harus dibuat dari susunan bilangan biner yang diletakkan sesuai urutan nomor klasifikasi. Baris pada matriks merupakan sampel dan kolom matriks merupakan nomor klasifikasi.

Tabel 2. Matrik Output Klasifikasi

\begin{tabular}{|c|c|c|}
\hline No. & Klasifikasi & Matrik \\
\hline 1 & Saya & 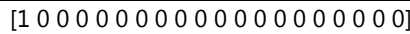 \\
\hline 2 & Kamu & 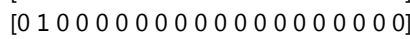 \\
\hline 3 & Bapak & 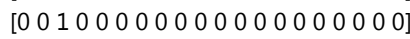 \\
\hline 4 & Ibu & 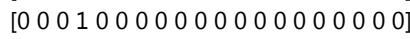 \\
\hline 5 & Adik & 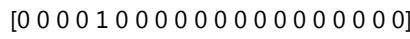 \\
\hline 6 & Tidur & 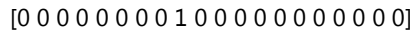 \\
\hline 7 & Bertemu & 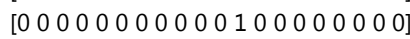 \\
\hline 8 & Apa & 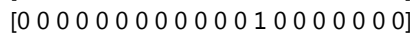 \\
\hline 9 & Maaf & 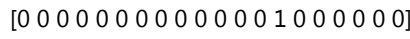 \\
\hline 10 & Hari Ini & 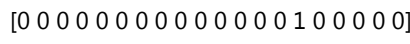 \\
\hline
\end{tabular}

\section{HASIL DAN PEMBAHASAN}

Pada penelitian ini, hasil pengujian dilakukan dengan cara melakukan semua gerakan secara bergantian. Masing-masing gerakan diulang sebanyak sepuluh kali. Setelah melakukan satu gerakan, maka akan diamati hasil klasifikasi berupa suara. Kemudian dihitung persentase keberhasilan dan rata-rata keberhasilan pada masing-masing gerakan dan persentase secara keseluruhan serta rata-rata keberhasilan pada semua gerakan.

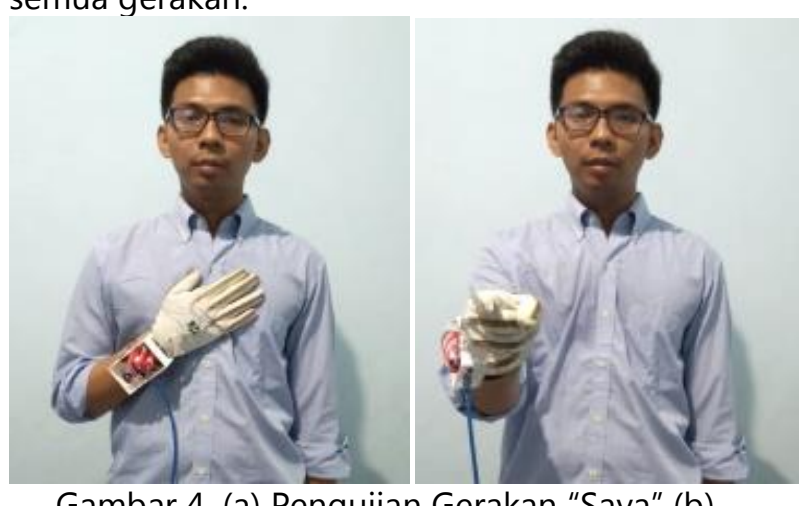

Gambar 4. (a) Pengujian Gerakan "Saya" (b) Pengujian Gerakan "Kamu"

Tabel 3. Hasil Pengujian Klasifikasi Gerakan"Saya"

\begin{tabular}{cccc}
\hline No & $\begin{array}{c}\text { Masukan } \\
\text { gerakan }\end{array}$ & $\begin{array}{c}\text { Keluaran } \\
\text { suara }\end{array}$ & $\begin{array}{c}\text { Persentase } \\
\text { keberhasilan(\%) }\end{array}$ \\
\hline 1 & Saya & Saya & 100 \\
2 & Saya & Saya & 100 \\
3 & Saya & Saya & 100 \\
4 & Saya & Saya & 100 \\
5 & Saya & Saya & 100 \\
6 & Saya & Saya & 100 \\
7 & Saya & Saya & 100 \\
8 & Saya & Saya & 100 \\
9 & Saya & Saya & 100 \\
10 & Saya & Saya & 100 \\
& & Rata-rata & $\mathbf{1 0 0}$ \\
\hline
\end{tabular}


Tabel 4. Hasil Pengujian Klasifikasi Gerakan "Kamu"

\begin{tabular}{cccc}
\hline No & $\begin{array}{c}\text { Masukan } \\
\text { gerakan }\end{array}$ & $\begin{array}{c}\text { Keluaran } \\
\text { suara }\end{array}$ & $\begin{array}{c}\text { Persentase } \\
\text { keberhasilan(\%) }\end{array}$ \\
\hline 1 & Kamu & Kamu & 100 \\
2 & Kamu & Kamu & 100 \\
3 & Kamu & Tidak Sesuai & 0 \\
4 & Kamu & Kamu & 100 \\
5 & Kamu & Kamu & 100 \\
6 & Kamu & Tidak Sesuai & 0 \\
7 & Kamu & Kamu & 100 \\
8 & Kamu & Kamu & 100 \\
9 & Kamu & Kamu & 100 \\
10 & Kamu & Kamu & 100 \\
& & Rata-Rata & 80 \\
\hline
\end{tabular}

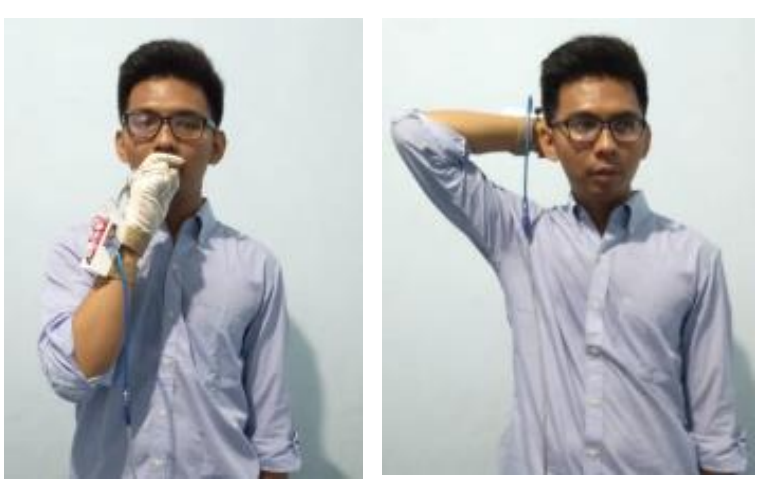

Gambar 5. (a) Pengujian Gerakan "Bapak"

(B) Pengujian Gerakan "Ibu"

Tabel 5. Hasil Pengujian Klasifikasi Gerakan "Bapak"

\begin{tabular}{|c|c|c|c|}
\hline No & $\begin{array}{c}\text { Masukan } \\
\text { gerakan }\end{array}$ & $\begin{array}{c}\text { Keluaran } \\
\text { suara }\end{array}$ & $\begin{array}{c}\text { Persentase } \\
\text { keberhasilan } \\
\text { (\%) }\end{array}$ \\
\hline 1 & Bapak & Bapak & 100 \\
\hline 2 & Bapak & Tidak Sesuai & 0 \\
\hline 3 & Bapak & Bapak & 100 \\
\hline 4 & Bapak & Bapak & 100 \\
\hline 5 & Bapak & Tidak Sesuai & 0 \\
\hline 6 & Bapak & Bapak & 100 \\
\hline 7 & Bapak & Bapak & 100 \\
\hline 8 & Bapak & Tidak Sesuai & 0 \\
\hline 9 & Bapak & Tidak Sesuai & 0 \\
\hline \multirow[t]{2}{*}{10} & Bapak & Bapak & 100 \\
\hline & & Rata-rata & 60 \\
\hline \multicolumn{4}{|c|}{ Tabel 6. Hasil Pengujian Klasifikasi Gerakan "Ibu' } \\
\hline No & $\begin{array}{l}\text { Masukan } \\
\text { gerakan }\end{array}$ & $\begin{array}{c}\text { Keluaran } \\
\text { suara }\end{array}$ & $\begin{array}{c}\text { Persentase } \\
\text { keberhasilan } \\
(\%)\end{array}$ \\
\hline 1 & Ibu & Tidak Sesuai & 0 \\
\hline 2 & Ibu & Tidak Sesuai & 0 \\
\hline 3 & Ibu & Ibu & 100 \\
\hline 4 & Ibu & Ibu & 100 \\
\hline 5 & Ibu & Tidak Sesuai & 0 \\
\hline 6 & Ibu & Tidak Sesuai & 0 \\
\hline 7 & Ibu & Tidak Sesuai & 0 \\
\hline 8 & Ibu & Tidak Sesuai & 0 \\
\hline 9 & Ibu & Tidak Sesuai & 0 \\
\hline \multirow[t]{2}{*}{10} & Ibu & Tidak Sesuai & 0 \\
\hline & & Rata-Rata & 20 \\
\hline
\end{tabular}
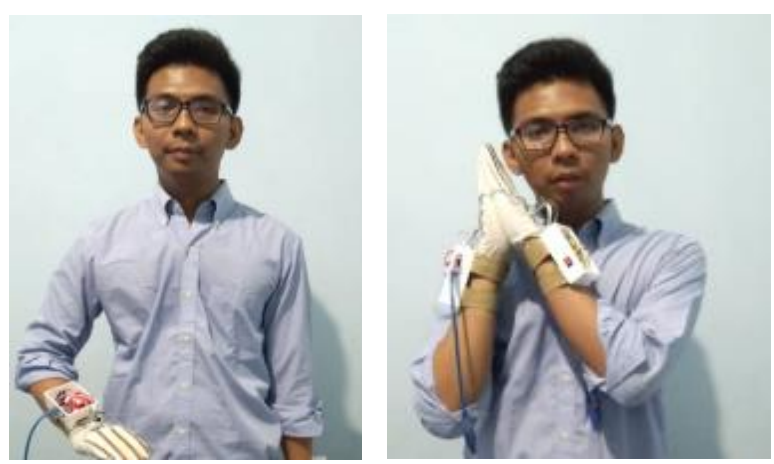

Gambar 6. (a) Pengujian Gerakan "Adik"

(b) Pengujian Gerakan "Tidur"

Tabel 7. Hasil Pengujian Klasifikasi Gerakan "Adik"

\begin{tabular}{cccc}
\hline No & $\begin{array}{c}\text { Masukan } \\
\text { gerakan }\end{array}$ & $\begin{array}{c}\text { Keluaran } \\
\text { suara }\end{array}$ & $\begin{array}{c}\text { Persentase } \\
\text { keberhasilan } \\
\text { (\%) }\end{array}$ \\
\hline 1 & Adik & Adik & 100 \\
2 & Adik & Adik & 100 \\
3 & Adik & Adik & 100 \\
4 & Adik & Adik & 100 \\
5 & Adik & Adik & 100 \\
6 & Adik & Adik & 100 \\
7 & Adik & Adik & 100 \\
8 & Adik & Adik & 100 \\
9 & Adik & Tidak Sesuai & 0 \\
10 & Adik & Adik & 100 \\
& & Rata-Rata & 90 \\
\hline
\end{tabular}

Tabel 8. Hasil Pengujian Klasifikasi Gerakan "Tidur"

\begin{tabular}{cccc}
\hline No & $\begin{array}{c}\text { Masukan } \\
\text { gerakan }\end{array}$ & $\begin{array}{c}\text { Keluaran } \\
\text { suara }\end{array}$ & $\begin{array}{c}\text { Persentase } \\
\text { keberhasilan(\%) }\end{array}$ \\
\hline 1 & Tidur & Tidur & 100 \\
2 & Tidur & Tidur & 100 \\
3 & Tidur & Tidur & 100 \\
4 & Tidur & Tidur & 100 \\
5 & Tidur & Tidur & 100 \\
6 & Tidur & Tidur & 100 \\
7 & Tidur & Tidur & 100 \\
8 & Tidur & Tidur & 100 \\
9 & Tidur & Tidak Sesuai & 0 \\
10 & Tidur & Tidak Sesuai & 0 \\
& & Rata-Rata & 80 \\
\hline
\end{tabular}

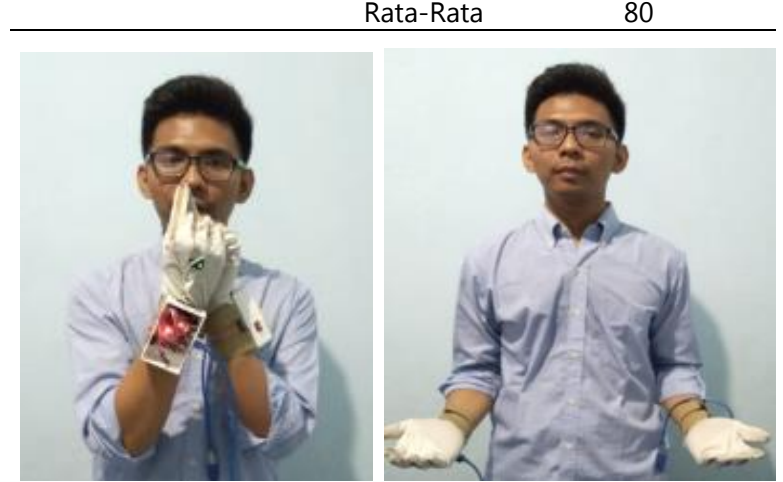

Gambar 7. (a) Pengujian Gerakan "Bertemu" (b) Pengujian Gerakan "Apa" 
Tabel 9. Hasil Pengujian Klasifikasi Gerakan "Bertemu"

\begin{tabular}{cccc}
\hline No & $\begin{array}{c}\text { Masukan } \\
\text { gerakan }\end{array}$ & $\begin{array}{c}\text { Keluaran } \\
\text { suara }\end{array}$ & $\begin{array}{c}\text { Persentase } \\
\text { keberhasilan } \\
\text { (\%) }\end{array}$ \\
\hline 1 & Bertemu & Bertemu & 100 \\
2 & Bertemu & Bertemu & 100 \\
3 & Bertemu & Bertemu & 100 \\
4 & Bertemu & Bertemu & 100 \\
5 & Bertemu & Bertemu & 100 \\
6 & Bertemu & Bertemu & 100 \\
7 & Bertemu & Bertemu & 100 \\
8 & Bertemu & Bertemu & 100 \\
9 & Bertemu & Bertemu & 100 \\
10 & Bertemu & Bertemu & 100 \\
& & Rata-Rata & 100 \\
\hline
\end{tabular}

Tabel 10. Hasil Pengujian Klasifikasi Gerakan "Apa"

\begin{tabular}{cccc}
\hline No & $\begin{array}{c}\text { Masukan } \\
\text { gerakan }\end{array}$ & $\begin{array}{c}\text { Keluaran } \\
\text { suara }\end{array}$ & $\begin{array}{c}\text { Persentase } \\
\text { keberhasilan(\%) }\end{array}$ \\
\hline 1 & Apa & Apa & 100 \\
2 & Apa & Apa & 100 \\
3 & Apa & Apa & 100 \\
4 & Apa & Apa & 100 \\
5 & Apa & Apa & 100 \\
6 & Apa & Apa & 100 \\
7 & Apa & Tidak Sesuai & 0 \\
8 & Apa & 100 \\
9 & Apa & $\begin{array}{c}\text { Tidak Sesuai } \\
\text { Tidak Sesuai }\end{array}$ & 0 \\
10 & Rata-Rata & 70 \\
\hline & & & \\
& & &
\end{tabular}

Gambar 8 (a) Pengujian Gerakan "Maaf"

(b) Pengujian Gerakan "Hari Ini"

Tabel 11.Hasil Pengujian Klasifikasi Gerakan "Maaf"

\begin{tabular}{cccc}
\hline No & $\begin{array}{c}\text { Masukan } \\
\text { gerakan }\end{array}$ & $\begin{array}{c}\text { Keluaran } \\
\text { suara }\end{array}$ & $\begin{array}{c}\text { Persentase } \\
\text { keberhasilan(\%) }\end{array}$ \\
\hline 1 & maaf & maaf & 100 \\
2 & maaf & tidak sesuai & 0 \\
3 & maaf & tidak sesuai & 0 \\
4 & maaf & maaf & 100 \\
5 & maaf & tidak sesuai & 0 \\
6 & maaf & maaf & 100 \\
7 & maaf & tidak sesuai & 0 \\
8 & maaf & maaf & 100 \\
9 & maaf & tidak sesuai & 0 \\
10 & maaf & maaf & 100 \\
& & Rata-rata & 50 \\
\hline
\end{tabular}

Tabel 12. Hasil Pengujian Klasifikasi Gerakan "Hari Ini"

\begin{tabular}{cccc}
\hline No & $\begin{array}{c}\text { Masukan } \\
\text { gerakan }\end{array}$ & $\begin{array}{c}\text { Keluaran } \\
\text { suara }\end{array}$ & $\begin{array}{c}\text { Persentase } \\
\text { keberhasilan(\%) }\end{array}$ \\
\hline 1 & Hari Ini & Hari Ini & 100 \\
2 & Hari Ini & Hari Ini & 100 \\
3 & Hari Ini & Hari Ini & 100 \\
4 & Hari Ini & Hari Ini & 100 \\
5 & Hari Ini & Hari Ini & 100 \\
6 & Hari Ini & Hari Ini & 100 \\
7 & Hari Ini & Hari Ini & 100 \\
8 & Hari Ini & Hari Ini & 100 \\
9 & Hari Ini & Tidak Sesuai & 0 \\
10 & Hari Ini & Hari Ini & 100 \\
& & Rata-Rata & 90 \\
\hline
\end{tabular}

Hasil uji menunjukkan bahwa pada gerakan saya mendapatkan rata-rata keberhasilan sebesar $100 \%$, gerakan kamu sebesar $80 \%$, gerakan bapak sebesar $60 \%$, gerakan ibu sebesar $20 \%$, gerakan adik sebesar $90 \%$, gerakan tidur sebesar $80 \%$, gerakan bertemu sebesar 100\%, gerakan apa sebesar $70 \%$, gerakan maaf sebesar $50 \%$, dan gerakan hari ini sebesar $90 \%$. Rata-rata secara keseluruhan adalah sebesar $74 \%$.

\section{KESIMPULAN DAN SARAN Kesimpulan}

Klasifikasi gerakan tangan menjadi suara menggunakan neural network telah berhasil dilakukan. Hasil klasifikasi memiliki beberapa variasi. Dari 10 gerakan percobaan, neural network hanya mampu mengklasifikasikan dua gerakan secara sempurna $100 \%$ yaitu "saya" dan "bertemu". Selain dua gerakan tersebut, masingmasing gerakan mendapat keberhasilan bervariasi. Hasil terendah adalah gerakan "ibu" yang hanya $20 \%$. Secara keseluruhan tingkat keberhasilannya adalah $74 \%$.

\section{DAFTAR PUSTAKA}

Hardjana, A. (2003). Komunikasi Intrapersonal Dan Komunikasi Interpersonal. Yogyakarta: Kanisius (p. 22)

Fajar, M. (2009). Ilmu Komunikasi Teori dan Praktek. Yogyakarta: Graha Ilmu (p. 81)

Rochmah, N.A \& Fitriyani, N. (2013). Proses Komunikasi Verbal dan Non Verbal. Skripsi. Universitas Islam Negeri Sunan Ampel Surabaya.

Nuryazid. (2016). Pengembangan Aplikasi Kamus Bahasa Isyarat Indonesia (Bisindo) Dengan 
Mengintegrasikan Cloud Video Berbasis Android. Tesis Universitas Negeri Semarang.

Hikmalansya, J.K. \& Cahyono, D. (2016). Aplikasi Pembelajaran Bahasa Isyarat Berbasis Android. Jurnal INFORM Vol.1 No 2: 118124.

López-Noriega, J.E., Fernández-Valladares, M.I \& V. Uc-Cetina. (2014). Glove-based sign language recognition solution to assist communication for deaf users. 2014 11th International Conference on Electrical Engineering, Computing Science and Automatic Control (CCE), Campeche. (p. 1$6)$.
Spectrasymbol Corp. (2014). Flex Sensor Fs. Salt Lake City, UTAH: Spectrasymbol Corp.

Bhaskaran, K.A., Nair, A.G Ram, K. Ananthanarayanan and H. R. N. Vardhan. (2016). Smart gloves for hand gesture recognition: Sign language to speech conversion system. 2016 International Conference on Robotics and Automation for Humanitarian Applications (RAHA), Kollam. (p. 1-6). 
Rekayasa, 13 (3): 2020 | 277 